\title{
Psychometric properties of a Swedish translation of the VISA-P outcome score for patellar tendinopathy
} Anna Frohm*1,2, Tönu Saartok², Gunnar Edman ${ }^{3}$ and Per Renström²

Address: ${ }^{1}$ Elite Sports Centre, Swedish Sports Confederation, Bosön, Sweden, ${ }^{2}$ Department of Surgical Sciences, Section of Sports Medicine, Karolinska Institute, SE-171 76 Stockholm, Sweden and 32Department of Psychiatry, R \& D Section, Danderyd Hospital, SE-182 87 Danderyd, Sweden

Email: Anna Frohm* - anna.frohm@rf.se; Tönu Saartok - tonu.saartok@kirurgi.ki.se; Gunnar Edman - gunnar.edman@psyk.nlpo.sll.se; Per Renström - per.renstrom@kirurgi.ki.se

* Corresponding author

Published: 18 December 2004

BMC Musculoskeletal Disorders 2004, 5:49 doi:10.1 |86/I47|-2474-5-49

Received: 07 July 2004

Accepted: 18 December 2004 (c) 2004 Frohm et al; licensee BioMed Central Ltd.

This is an Open Access article distributed under the terms of the Creative Commons Attribution License (http://creativecommons.org/licenses/by/2.0), which permits unrestricted use, distribution, and reproduction in any medium, provided the original work is properly cited.

\begin{abstract}
Background: Self-administrated patient outcome scores are increasingly recommended for evaluation of primary outcome in clinical studies. The VISA-P score, developed at the Victorian Institute of Sport Assessment in Melbourne, Australia, is a questionnaire developed for patients with patellar tendinopathy and the patients assess severity of symptoms, function and ability to participate in sport. The aim of this study was to translate the questionnaire into Swedish and to study the reliability and validity of the translated questionnaire and resultant scores.
\end{abstract}

Methods: The questionnaire was translated into Swedish according to internationally recommended guidelines for cross-cultural adaptation of self-report measures. The reliability and validity were tested in three different populations. The populations used were healthy students (n $=17)$, members of the Swedish male national basketball team $(n=17)$, considered as a population at risk, and a group of non-surgically treated patients $(n=17)$ with clinically diagnosed patellar tendinopathy. The questionnaire was completed by $5 \mathrm{I}$ subjects altogether.

Results: The translated VISA-P questionnaire showed very good test-retest reliability (ICC = 0.97).

The mean $( \pm S D)$ of the VISA-P score, at both the first and second test occasions was highest in the healthy student group $83( \pm 13)$ and $81( \pm 15)$, respectively. The score of the basketball players was $79( \pm 24)$ and $80( \pm 23)$, while the patient group scored significantly $(p<0.05)$ lower, $48( \pm$ $20)$ and $52( \pm 19)$.

Conclusions: The translated version of the VISA-P questionnaire was linguistically and culturally equivalent to the original version. The translated score showed good reliability.

\section{Background \\ Patellar tendinopathy}

Patellar tendinopathy affects athletes in many sports and at all levels of participation, but is of particular concern for elite jumping athletes [1]. Many different types of sport activities have an increased risk for overuse of the patellar tendon including endurance sports (e.g. long-distance running and cross-country skiing) and sports with 
repetitive demands on strength and technique (e.g. tennis, baseball, volleyball, basketball and ballet) [2]. Athletes who participate in these sports may develop anterior knee pain that presents as tenderness at the inferior pole of the patella. This clinical syndrome is commonly called Jumper's knee, or patellar tendinopathy [3]. The term tendinopathy is considered to be the most appropriate clinical description for these chronic painful tendon conditions since there is no evidence of an inflammatory reaction in the chronically degenerated tendon $[4,5]$. The changes in the tendon are mainly due to chronic collagen fiber degeneration [6], but the cause and source of the pain still remains unclear.

There are few studies on non-surgical treatment of patellar tendinopathy and there is a lack of evidence-based knowledge evaluating the therapy [7]. In-vivo studies in human or animals indicate possible benefits from treatments like heavy pressure [8], therapeutic ultrasound [9] and eccentric strength training [10-14].

\section{Self-rated inventories for knee function}

Patient-administrated questionnaires are frequently applied as primary outcome measures in clinical trials and several inventories have been translated from English into Swedish [15-17]. The WOMAC osteoarthritis index has been tested for reliability and validity in Sweden [18] and compared to quality of life instruments (SF-36 and NHP) [19]. The Knee injury and Osteoarthritis Outcome Score (KOOS) is also a self-administrated instrument measuring outcome after knee injury at impairment, disability, and handicap level with five subscales [16]. Garratt et al determined that KOOS showed good evidence of reliability, validity and responsiveness, and is recommended the score for knee diagnosis like ACL reconstruction, total knee replacements and for arthroplasty patients [20]. The only published clinical scale for patellar tendinopathy problems (VISA-P) was developed in Australia by the Victorian Institute of Sport Assessment in Melbourne [21]. The aim was to assess symptoms, simple tests of function and the ability of subjects to undertake sports. This selfadministrated questionnaire has been documented as a reliable instrument for monitoring the progress of rehabilitation $[3,7]$. It has also been shown to be a valuable tool in the assessment and documentation of recovery from patellar tendinopathy [22]. Even so, the responsiveness and validity of the questionnaire have not yet been fully proven.

The purpose of this study was to translate and cross-culturally adapt the VISA-P score for a Swedish population and to perform a psychometric analysis as well as reliability and initial validity testing of the Swedish VISA-P score.

\section{Methods Subjects}

Fifty-one subjects gave informed consent to participate in this study. The VISA-P score was administered to 17 healthy students [ 9 women, 8 men, mean age $( \pm$ SD) 24 $( \pm 6)$ ]; a population at risk, the Swedish male national basketball team [17 men, mean age $26( \pm 3)]$, and patients with the diagnosis patellar tendinopathy [17 men, mean age $22( \pm 5)]$.

The study was approved by the Ethical Committee at the Medical Faculty of the Karolinska Institute, Stockholm (Dnr 00-103).

\section{The VISA-P score}

The VISA-P score consists of eight questions [21], of which six questions concern pain experienced during a range of everyday activities. Two questions deal with the ability to engage in sport activities. All questions are answered on separate scales $(0-10)$, where a higher score indicates a lower level of pain or impairment (Appendix A) [see additional file 1]. The maximal total score is 100 points, which would indicate that the person has no knee pain, good function and can perform fully in sports. The theoretical minimum score is 0 points.

The original VISA-P score lacks information about the selection of items, weighting of each answer and the ranking of the options in the subscales in question 8.

The aim of the present investigation was to get a "working tool" for further studies of the usefulness of the instrument for patellar tendinopathy patients in Sweden.

\section{Translation procedure}

The VISA Tendon Study Group at the University of Melbourne in Australia was informed and gave their consent to a Swedish translation of their original VISA-P score (Karim Khan, personal communication, 2003).

The translation process followed the method described by Beaton et al [23]. This method is currently used by a number of organizations, including the American Association of Orthopaedic Surgeons (AAOS) Outcomes Committee as they coordinate translations of the different components of their outcome batteries [23]. The translation process is divided into five different stages: (I) Translation, (II) Synthesis, (III) Reverse translation, (IV) Expert committee review and (V) Pre-testing.

Initially, two physiotherapists performed two independent translations (I) from English into Swedish. A synthesis (II) of these translations was made, and the consensus of the two translated Swedish versions was documented. Reverse translations (III) were performed independently 
by three native Anglophones fluent in Swedish. One of the reverse translators was a physiotherapist, one was an economist and the third was a teacher. The three physiotherapists in the expert committee (IV) then made a semantic and idiomatic equivalence analysis between the original source and target Swedish version of the VISA-P questionnaire. The translated questionnaire was pretested (V) on 12 individuals, six patients with patellar tendinopathy and six physical education students.

\section{Test-retest reliability}

The Swedish VISA-P score (Appendix B) [see additional file 2] was administrated to all 51 participants at Bosön, the Swedish National Sports Confederation Centre (Lidingö, Sweden). The participants completed the questionnaire twice within an interval of one week (range 4-7 days).

The principal investigator administrated the questionnaires at all test occasions, with the exception of six of the tendinopathy patients.

\section{Validity}

For validity, the factor structure of the VISA-P score was analyzed with a principal component analysis, Varimax rotation. The number of extracted factors was equal to the number of eigen values above 1.00. Internal consistency of subscales, based on the factor analysis, and the total scale was calculated as a Cronbach $\alpha$ coefficient [24].

For discriminative validity of the VISA-P questionnaires were compared between three groups, each of which were expected to have different levels of scoring.

\section{Statistics}

All variables were summarized according to standard descriptive methods [mean and standard deviation (SD)] and checked for outliers. No significant deviations from the normal distribution criterion were found. The testretest reliability was analyzed according to the method described by Bland and Altman, which yields an intraclass correlation (ICC) [25]. Differences between test occasions and groups were analyzed with an ANOVA (analysis of variance for repeated measurements, group *time). In the post-hoc tests of group differences, Tukey's HSD method was applied. A significance level of five percent was applied (two-tailed).

\section{Results}

\section{Translation}

The expert committee considered the translation and reverse translation satisfactory.

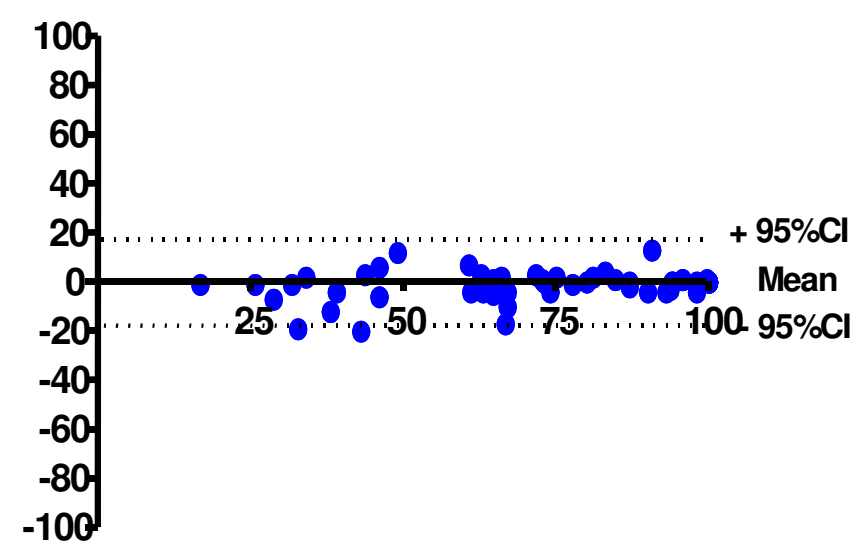

\section{Figure I}

Bland-Altman plot of the Swedish VISA-P score in the reliability (test-retest within I week) investigation. Each blue dot indicates the difference in the total score, in relation to the mean score, between the two assessments.

\section{Test-retest reliability}

The test-retest of the Swedish VISA-P score showed high reliability and significance (ICC $=0.97, \mathrm{p}<0.001$ ). In Figure 1 , the Bland-Altman plot is showing the difference in total score between occasion one (A) and occasion two (B), plotted against the mean value of both test occasions. There were no significant differences for the total VISA-P score between the first and second test occasions. Each question (Q) was analyzed separately regarding the reliability. Seven out of eight questions has a reliability of more than ICC $=0.8$ (range 0.68-0.97).

The score was easy to use and it took about five minutes to complete.

\section{Internal consistency}

The internal consistency of the total scale was high for the scores both at the first and second occasion, 0.83 and 0.82 , respectively.

\section{Factor structure}

The principal component analysis yielded a two-factor solution. The communality, i.e. the degree of explained variance, of one of the questions (Table 1, "sit pain-free?") was below 0.35 , and thus not sufficiently explained by this solution. Thus, a three-factor solution was preferred which explained $85 \%$ of the total variance, with all communalities above 0.60 . The first component comprised of six questions. The second and third components comprised of one question each. This solution showed high 
Table I: Three-factor solution according to a principal component analysis, Varimax rotation. The questions are ordered after their factor loading.

\begin{tabular}{|c|c|c|c|c|}
\hline \multirow[b]{2}{*}{ Question } & \multicolumn{3}{|c|}{ Component } & \multirow[b]{2}{*}{$h^{2}$} \\
\hline & 1 & II & III & \\
\hline Q4. Do you have pain when doing a full weight bearing lunge? & 0.92 & 0.18 & 0.06 & 0.88 \\
\hline Q5. Do you have problems squatting? & 0.90 & -0.09 & 0.25 & 0.88 \\
\hline Q6. Do you have pain during or immediately after doing 10 single leg hops? & 0.88 & 0.13 & 0.26 & 0.86 \\
\hline Q3. Do you have pain at the knee with full active non-weight bearing knee extension? & 0.77 & 0.26 & 0.12 & 0.68 \\
\hline Q8. For how long can you manage being train/physically active? & 0.75 & 0.39 & 0.11 & 0.73 \\
\hline Q2. Do you have pain walking downstairs with a normal gait cycle? & 0.70 & 0.38 & 0.24 & 0.69 \\
\hline QI. For how many minutes can you sit pain free? & 0.23 & 0.13 & 0.96 & 0.99 \\
\hline Q7. Are you currently undertaking sport or other physical activity? & 0.17 & 0.95 & 0.11 & 0.94 \\
\hline
\end{tabular}

stability, being invariant in a second factor analysis of the scores from the second occasion (the amount of explained variance was $83 \%)$.

\section{Group differences in the VISA-P score}

At the first test occasion (A) the mean $( \pm$ SD) of the VISAP score in the healthy student group was $83( \pm 12)$, in the basketball players $79( \pm 23)$, and $47( \pm 20)$ in the patient group (Table 2). In all questions, the patient group had lower scores as compared to the other two groups and statistical significance $(\mathrm{p}<0.05)$ was observed in all individual questions except the first ("sit pain-free"). In Table 1 the post-hoc tests for group differences are presented. The questions concerning pain ("pain during 10 single leg hops") had the greatest difference between the groups (F $=12.7, \mathrm{p}<0.001$ ). Both activity questions ("currently undertaking sport" and" pain during activity") showed significant $(\mathrm{p}<0.001)$ differences between the groups.

\section{Discussion \\ Translation}

The expert committee of the translation process expressed a general agreement of all the questions except one (Q1). During the translation procedure of the VISA-P score, the translation for "pain" was debated. Different Swedish words were discussed and compared between the different translators. Translations into the mother tongue, or the first language, more accurately reflected the nuances of the language. Reverse translation into English of the Swedish VISA-P version was without remarks. Thus, the original and translated versions were judged by the expert committee to be congruent.

\section{Test-retest reliability}

Over a time interval of one week (range 4-7 days), the Swedish version of the VISA-P score showed high reliability $(\mathrm{ICC}=0.97)$. As compared to other test-retest investi- gations of this score, this interval is the longest that has been studied [21].

\section{Validation of the VISA-P}

A factor analysis yielded three factors, of which the first showed the highest correlations with two questions ("pain during a full weight bearing lunge" and "problems squatting", see Table 1). The two other factors comprised only one question each, "currently undertaking sport" and "sitting pain-free", respectively. The separate factor for the question about "sitting pain-free" may be an artefact, as this item was the first one where misperceptions of the response dimension were more likely, thereby increasing the risk of higher error or unique variance. Some subjects in the pre-testing group, reported that they had perceived high scores as more pain. Conceptually, this question is equivalent to the questions of the first component. Experiences from the pre-testing resulted in a more detailed instruction for filling out the Swedish questionnaire.

\section{Group difference}

The patellar tendinopathy patients scored lower for all questions in the VISA-P score. The basketball players scored higher than the healthy students in two questions ("sitting pain-free" and "currently undertaking sport", see Table 2). The first question was the only question that did not show any statistical significance between the groups and, noteworthy, the lowest score, i.e. highest degree of problem. The reason given above regarding the risk of misperception of the response dimension might be an explanation. 
The VISA-P score has not yet been validated for patholog-

Table 2: Mean score and standard deviation (SD) in three groups of subjects: patients with patellar tendinopathy (P); basket-ball players (B); and healthy students $(H)$, and analysis of variance (ANOVA) of group differences of the Swedish VISA score.

\begin{tabular}{|c|c|c|c|c|c|c|c|c|c|c|c|c|}
\hline \multirow[b]{2}{*}{ Question } & \multirow[b]{2}{*}{ Occasion } & \multicolumn{2}{|c|}{ Patients $(n=17)$} & \multicolumn{2}{|c|}{ Basketball $(n=17)$} & \multicolumn{2}{|c|}{ Healthy student $(n=17)$} & \multicolumn{2}{|c|}{ Total $(n=5 I)$} & \multicolumn{3}{|c|}{ ANOVA } \\
\hline & & $M$ & $S D$ & $M$ & $S D$ & $M$ & $S D$ & $M$ & $S D$ & $F$ & $p$ & Tukey \\
\hline \multirow{2}{*}{$\begin{array}{l}\text { QI. For how many } \\
\text { minutes can you sit } \\
\text { pain free? }\end{array}$} & A & 5.41 & 2.94 & 7.53 & 2.88 & 7.24 & 3.52 & 6.73 & 3.21 & 2.29 & n.s & ns \\
\hline & B & 6.06 & 2.80 & 7.82 & 2.65 & 7.18 & 3.63 & 7.02 & 3.08 & & & \\
\hline \multirow{2}{*}{$\begin{array}{l}\text { Q2. Do you have pain } \\
\text { walking down-stairs } \\
\text { with a normal gait } \\
\text { cycle? }\end{array}$} & $A$ & 5.94 & 2.35 & 8.47 & 2.81 & 8.94 & 1.34 & 7.78 & 2.58 & 8.70 & $p<0.001$ & $P<B ; P<H$ \\
\hline & B & 6.94 & 2.02 & 8.82 & 1.98 & 8.41 & 2.18 & 8.06 & 2.18 & & & \\
\hline \multirow{2}{*}{$\begin{array}{l}\text { Q3. Do you have pain } \\
\text { at the knee with full } \\
\text { active non-weight } \\
\text { bearing knee } \\
\text { extension? }\end{array}$} & A & 6.59 & 3.00 & 8.47 & 2.53 & 9.53 & 1.06 & 8.20 & 2.61 & 6.84 & $P<0.05$ & $\mathrm{P}<\mathrm{H}$ \\
\hline & B & 6.29 & 2.44 & 8.82 & 1.97 & 9.18 & 1.33 & 8.10 & 2.33 & & & \\
\hline \multirow{2}{*}{$\begin{array}{l}\text { Q4. Do you have pain } \\
\text { when doing a full } \\
\text { weight bearing lunge? }\end{array}$} & $A$ & 4.41 & 2.89 & 7.65 & 3.08 & 8.06 & 2.19 & 6.71 & 3.16 & 8.97 & $p<0.05$ & $\mathrm{P}<\mathrm{B} ; \mathrm{p}<\mathrm{H}$ \\
\hline & B & 5.24 & 2.86 & 7.88 & 2.83 & 8.00 & 2.24 & 7.04 & 2.91 & & & \\
\hline \multirow{2}{*}{$\begin{array}{l}\text { Q5. Do you have } \\
\text { problems squatting? }\end{array}$} & A & 5.76 & 2.28 & 7.35 & 3.26 & 8.24 & 1.98 & 7.12 & 2.71 & 4.05 & $\mathrm{P}<0.05$ & $\mathrm{P}<\mathrm{H}$ \\
\hline & $B$ & 6.65 & 2.47 & 7.76 & 2.88 & 8.18 & 2.27 & 7.53 & 2.58 & & & \\
\hline \multirow{2}{*}{$\begin{array}{l}\text { Q6. Do you have pain } \\
\text { during or immediately } \\
\text { after doing } 10 \text { single } \\
\text { leg hops? }\end{array}$} & A & 3.29 & 2.33 & 6.65 & 3.62 & 8.18 & 2.55 & 6.04 & 3.50 & 12.6 & $\mathrm{p}<0.001$ & $\mathrm{P}<\mathrm{B} ; \mathrm{p}<\mathrm{H}$ \\
\hline & B & 4.29 & 2.87 & 6.71 & 3.88 & 8.18 & 2.04 & 6.39 & 3.38 & & & \\
\hline \multirow{2}{*}{$\begin{array}{l}\text { Q7. Are you } \\
\text { currently undertaking } \\
\text { sport or other } \\
\text { physical activity? }\end{array}$} & A & 5.00 & 2.48 & 9.47 & 1.58 & 7.35 & 2.98 & 7.27 & 3.00 & 14.5 & $p<0.001$ & $\mathrm{P}<\mathrm{H}<\mathrm{B}$ \\
\hline & B & 4.41 & 2.62 & 9.47 & 1.58 & 7.00 & 2.81 & 6.96 & 3.14 & & & \\
\hline \multirow{2}{*}{$\begin{array}{l}\text { Q8. For how long can } \\
\text { you manage being } \\
\text { train/physically active? }\end{array}$} & A & 11.35 & 10.94 & 23.41 & 8.27 & 25.53 & 5.68 & 20.10 & 10.50 & 13.5 & $p<0.001$ & $\mathrm{p}<\mathrm{B} ; \mathrm{p}<\mathrm{H}$ \\
\hline & B & 12.41 & 10.25 & 22.82 & 8.13 & 25.53 & 5.68 & 20.25 & 9.86 & & & \\
\hline \multirow[t]{2}{*}{ Total score } & A & 47.76 & 20.26 & 79.00 & 24.18 & 83.06 & 12.60 & 69.94 & 24.96 & 16.4 & $p<0.001$ & $\mathrm{P}<\mathrm{B} ; \mathrm{p}<\mathrm{H}$ \\
\hline & B & 52.29 & 18.98 & 80.12 & 22.82 & 81.65 & 15.48 & 71.35 & 23.33 & & & \\
\hline
\end{tabular}

ical knee conditions other than patellar tendinopathy. Considering the separate questions (Appendix A) [see additional file 1] it would be of interest to test the VISA-P score for patients with anterior knee pain other than patellar tendinopathy.

The significantly higher scores of the basketball players in question 7, "currently undertaking sport" (Table 2) were trivial and obvious, since all of them were active players in Swedish the national team. The standard deviation was nearly twice as high for the patients and basketball players as compared to the healthy students. This reflects the heterogeneity of the first two groups.

Generally, there is a debate concerning scores about the relevance of using the total score or dividing the score in different subgroups. A short clinical scale is often an advantage. The factor analysis as well as the analysis of differences between the groups suggests that the VISA-P score 
could be abbreviated to two or three items without losing significant clinical information (Table 1).

An important aspect of a clinical scale is its sensitivity for change or its ability to follow amelioration or exacerbation during treatment. The theoretical range of the VISA score, i.e. the floor and ceiling, is $0-100$. The mean total score of the patients was approximately 50 (with a minimum value of 16) and for the control groups 80 (with a maximum value of 100 . Thus, there seems to be sufficient scope to follow treatment effects, as well as to follow deteriorations of a risk group. It should be noted, however, that the present study was not designed to study treatment effects or development of a pathological process. The conclusion regarding the sensitivity of the VISA score, thus, awaits empirical support.

Although the mean VISA-P scoring was significantly different between asymptomatic subjects and patients with patellar tendinopathy, the score is not suggested to be a diagnostic test [21]. Therefore the score is considered to be suitable for group and intra-individual comparisons but should be avoided in inter-individual comparison. Another limitation of the score has not been shown to be applicable in a non-athletic population.

Adaptation of a questionnaire for use in a new setting is time consuming and costly. There are specific criteria that investigators should apply when evaluating patient-based outcome measures [26]. That being the case, larger international data collections and better correlations can be made when proper translations are performed and evaluations conducted. Additionally, there is a need for international accepted 'golden standards' in outcome scores.

In conclusion, the results of the present study suggest that the translated Swedish version (Appendix B) [see additional file 2] of the original Australian VISA-P score (Appendix A) [see additional file 1] had satisfactory testretest reliability when used to evaluate symptoms, tests of function and ability to undertake sport in patients with patellar tendinopathy.

\section{Authors' contributions}

AF initiated the study, led the translation process and conducted all test occasions. TS and PR helped with general analysis and writing the article. GE guided and helped the main author with the statistical analyses of the data collected. All four of the authors read and approved the article.

\section{Additional material}

\section{Additional File 1}

Appendix A. The original VISA-P score.

Click here for file

[http://www.biomedcentral.com/content/supplementary/1471-

2474-5-49-S1.doc]

\section{Additional File 2}

Appendix B. The translated and cross-culturally adapted Swedish VISA-P score.

Click here for file

[http://www.biomedcentral.com/content/supplementary/1471-

2474-5-49-S2.doc]

\section{Acknowledgements}

The help and encouragement I got from my colleagues at the Sport Medicine Section, Institution of Surgical Sciences, Karolinska Institutet, Stockholm, and at the Elite Sports Centre, Swedish Sports Confederation, Bosön, Lidingö, Sweden is highly appreciated.

\section{References}

I. Cook JL, Khan KM: What is the most appropriate treatment for patellar tendinopathy? Br J Sports Med 200I, 35:291-294.

2. Blazina ME, Kerlan RK, Jobe FW, Carter VS, Carlson GJ: Jumper's knee. Orthop Clin North Am 1973, 4:665-678.

3. Khan KM, Maffulli N, Coleman BD, Cook JL, Taunton JE: Patellar tendinopathy: some aspects of basic science and clinical management. Br J Sports Med 1998, 32:346-355.

4. Kraushaar BS, Nirschl RP: Tendinosis of the elbow (tennis elbow). Clinical features and findings of histological, immunohistochemical, and electron microscopy studies. J Bone Joint Surg Am 1999, 8 I:259-278.

5. Khan KM, Cook JL, Kannus P, Maffulli N, Bonar SF: Time to abandon the "tendinitis" myth. Bmj 2002, 324:626-627.

6. Jarvinen M, Jozsa L, Kannus P, Jarvinen TL, Kvist M, Leadbetter W: Histopathological findings in chronic tendon disorders. Scand J Med Sci Sports 1997, 7:86-95.

7. Cook JL, Khan KM, Purdam CR: Conservative treatment of patellar tendinopathy. Physical Therapy in Sport 200I, 2:54-65.

8. Gehlsen GM, Ganion LR, Helfst R: Fibroblast responses to variation in soft tissue mobilization pressure. Med Sci Sports Exerc |999, 31:53|-535.

9. Ramirez A, Schwane JA, McFarland C, Starcher B: The effect of ultrasound on collagen synthesis and fibroblast proliferation in vitro. Med Sci Sports Exerc 1997, 29:326-332.

10. Stanish WD, Rubinovich RM, Curwin S: Eccentric exercise in chronic tendinitis. Clin Orthop 1986:65-68.

II. Jensen K, Di Fabio RP: Evaluation of eccentric exercise in treatment of patellar tendinitis. Phys Ther 1989, 69:211-216.

12. el Hawary R, Stanish WD, Curwin SL: Rehabilitation of tendon injuries in sport. Sports Med 1997, 24:347-358.

13. Stasinopoulos D, Stasinopoulos I: Comparison of effects of exercise programme, pulsed ultrasound and transverse friction in the treatment of chronic patellar tendinopathy. Clin Rehabil 2004, 1 8:347-352.

14. Cannell LJ, Taunton JE, Clement DB, Smith C, Khan KM: A randomised clinical trial of the efficacy of drop squats or leg extension/leg curl exercises to treat clinically diagnosed jumper's knee in athletes: pilot study. Br J Sports Med 200I, 35:60-64.

15. Lomi C, Burckhardt C, Nordholm L, Bjelle A, Ekdahl C: Evaluation of a Swedish version of the arthritis self-efficacy scale in people with fibromyalgia. Scand J Rheumatol 1995, 24:282-287.

16. Roos EM, Roos HP, Ekdahl C, Lohmander LS: Knee injury and Osteoarthritis Outcome Score (KOOS)--validation of a Swedish version. Scand J Med Sci Sports 1998, 8:439-448. 
17. Kjellberg A, Haglund L, Forsyth K, Kielhofner G: The measurement properties of the Swedish version of the assessment of communication and interaction skills. Scand J Caring Sci 2003, I7:27|-277.

18. Roos EM, Klassbo M, Lohmander LS: WOMAC osteoarthritis index. Reliability, validity, and responsiveness in patients with arthroscopically assessed osteoarthritis. Western Ontario and MacMaster Universities. Scand J Rheumatol 1999, 28:210-2I5

19. Soderman P, Malchau H: Validity and reliability of Swedish WOMAC osteoarthritis index: a self-administered diseasespecific questionnaire (WOMAC) versus generic instruments (SF-36 and NHP). Acta Orthop Scand 2000, 71:39-46.

20. Garratt AM, Brealey S, Gillespie WJ: Patient-assessed health instruments for the knee: a structured review. Rheumatology (Oxford) 2004, 43:|4|4-23.

21. Visentini PJ, Khan KM, Cook JL, Kiss ZS, Harcourt PR, Wark JD: The VISA score: an index of severity of symptoms in patients with jumper's knee (patellar tendinosis). Victorian Institute of Sport Tendon Study Group. J Sci Med Sport 1998, I:22-28.

22. Khan KM, Visentini PJ, Kiss ZS, Desmond PM, Coleman BD, Cook JL, Tress BM, Wark JD, Forster BB: Correlation of ultrasound and magnetic resonance imaging with clinical outcome after patellar tenotomy: prospective and retrospective studies. Victorian Institute of Sport Tendon Study Group. Clin J Sport Med 1999, 9: 129-137.

23. Beaton DE, Bombardier C, Guillemin F, Ferraz MB: Guidelines for the process of cross-cultural adaptation of self-report measures. Spine 2000, 25:3186-3191.

24. Cronbach LJ: Coefficient alpha and the internal structure of tests. Psychometrika 1951, 16:297-334.

25. Bland JM, Altman DG: Measurement error. Bmj 1996, 3 I3:744.

26. Fitzpatrick R, Davey C, Buxton MJ, Jones DR: Evaluating patientbased outcome measures for use in clinical trials. Health Technol Assess 1998, 2:i-iv, I-74.

\section{Pre-publication history}

The pre-publication history for this paper can be accessed here:

http://www.biomedcentral.com/1471-2474/5/49/prepub

\section{Publish with Bio Med Central and every scientist can read your work free of charge}

"BioMed Central will be the most significant development for disseminating the results of biomedical research in our lifetime. "

Sir Paul Nurse, Cancer Research UK

Your research papers will be:

- available free of charge to the entire biomedical community

- peer reviewed and published immediately upon acceptance

- cited in PubMed and archived on PubMed Central

- yours - you keep the copyright 